\title{
Research on PMSM Demagnetized by Three Phase Symmetrical Short Circuit
}

\author{
S. Huang \\ State Key Laboratory of Power Transmission Equipment \& \\ System Security and New Technology \\ Chongqing University \\ Chongqing, China \\ C. Zeng \\ State Key Laboratory of Power Transmission Equipment \& \\ System Security and New Technology \\ Chongqing University \\ Chongqing, China
}

\author{
X.P. Yan \\ State Key Laboratory of Power Transmission Equipment \& \\ System Security and New Technology \\ Chongqing University \\ Chongqing, China \\ Y.M. Yang \\ State Key Laboratory of Power Transmission Equipment \& \\ System Security and New Technology \\ Chongqing University \\ Chongqing, China
}

\begin{abstract}
The partial demagnetization of surface-mounted permanent magnets of PMSM in the three phase symmetrical short circuit of different temperature is analyzed by the finite element method. Then, rules of the back EMF and flux change in different extent of demagnetization are summarized. Finally, the operation behaviors and secondary demagnetization of the demagnetized PMSM are analyzed. Conclusion, which can judge and prevent demagnetization fault, is presented.
\end{abstract}

Keywords- partial demagnetization; three phase symmetrical short circuit; PMSM; operation in fault

\section{INTRODUCTION}

Compared with traditional electric exciter, permanent magnet synchronous motor (PMSM) has the advantages of simple structure, reliable operation, small size, light weight, little loss, high power density and flexible shape [1]. At present, the PMSM development has a trend of being large in scale, high energy saving, high performance and miniaturization [2]. With the operating environment being more complicated, the demand of safety and reliability is getting higher [3].

Because of the poor thermal stability and the negative temperature coefficient of the coercivity, PMSM of NdFeB magnets which is wildly used in civil industry field will suffer a different impact from traditional electric exciter when winding fault happens [4]. Especially the transient current impact, it may leads a partial irreversible demagnetization which is hard to monitor directly [5].

Therefore, it becomes an important subject in the field of PMSM to detect the demagnetization earlier and take protective measures to reduce the cost of maintenance and reduce economic loss [6]. For now, researches on demagnetization of PMSM caused by the winding fault are relatively few. Literature [7] proposed that divide the PM to several pieces in the axial direction and filled with different material respectively to simulate the demagnetization in the axial direction and it extracted the waveform of no-load EMF and flux to be the characteristic parameter. However the fault model is not practical and the harmonic waves are not considered in this paper. Literature $[8,9]$ compared the back EMF and torque in four different extent of demagnetization, the conclusion is meaningful to online monitoring of PMSM. But neither the basis of the demagnetization is given, nor the adjustment of controller is considered.

In view of the above shortcomings, the finite element method (FEM) is adopted and a transient model of a surfacemounted permanent magnets PMSM is built. Based on the analysis of three-phase symmetrical short circuit transient, the demagnetization of PM in different temperature is analyzed. The waveforms of back EMF and flux in different extent of demagnetization are obtained. The current, torque and risk of secondary demagnetization are analyzed when demagnetized PMSM continues operating.

\section{THE MODEL OF PMSM}

In order to analyze the demagnetization of the PM in threephase symmetrical short circuit, a 1/6 model of a surfacemounted PMSM with 6 poles and 36 slots is built, as shown in fig.1. Here, 1 is stator core, 2 is the PM, 3 is stator winding, 4 is air gap, 5 is rotor core and 6 is shaft. The main parameters is shown in Table.1. NdFeB magnets (grade of N35SH) are used in this motor and the characteristic curve of the magnets in different temperature is shown in fig.2. The inflection point of irreversible demagnetization is at the magnetic flux density of $0.2 \mathrm{~T}, 0.3 \mathrm{~T}$ and $0.4 \mathrm{~T}$. 


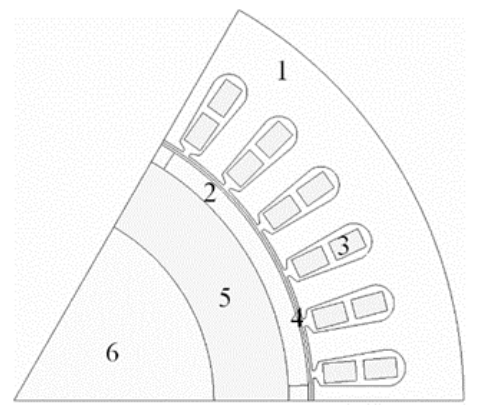

FIGURE I. THE 1/6 MODEL OF PMSM.

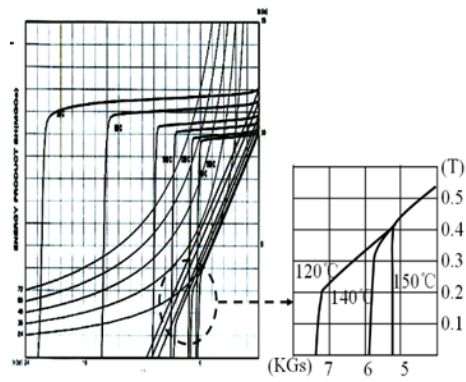

FIGURE II. MAGNETIZATION CURVE OF N35SH.

TABLE I. DESIGN PARAMETERS OF THE PMSM

\begin{tabular}{|c|c|c|c|}
\hline Power & Voltage & Speed & Torque \\
\hline $1400 \mathrm{~W}$ & $100 \mathrm{~V}$ & $3200 \mathrm{rpm}$ & $4 \mathrm{Nm}$ \\
\hline $\begin{array}{c}\text { Thickness of } \\
\text { PM }\end{array}$ & $\begin{array}{c}\text { Length of } \\
\text { armature }\end{array}$ & $\begin{array}{c}\text { Number of } \\
\text { poles/slots }\end{array}$ & Diameter \\
\hline $2 \mathrm{~mm}$ & $125 \mathrm{~mm}$ & $6 / 36$ & $90 \mathrm{~mm}$ \\
\hline
\end{tabular}

III. DEMAGNETIZATION AT THREE-PHASE SYMMETRICAL SHORT CIRCUIT

\section{A. Demagnetization Fault and the Fault Model}

According to the FEM model of the motor, the transient process of three-phase symmetrical short circuit occurred is calculated in the rated operation. When the demagnetization reaches the maximum, the distribution of magnetic flux density on the PM in different temperature is shown in fig.3. The dotted line pointed out the region of irreversible demagnetization. The magnetic flux density here is below the infection point.

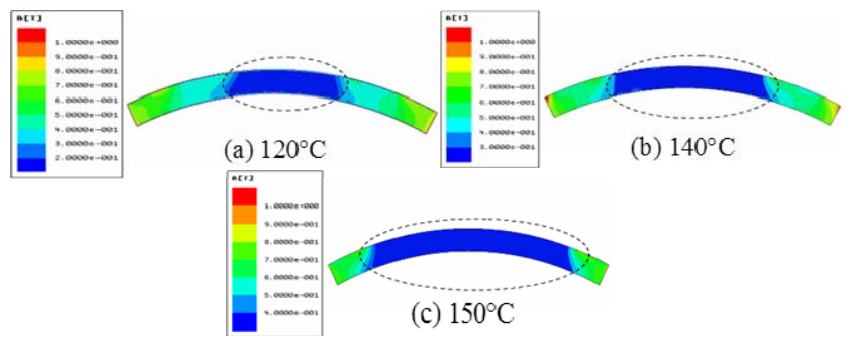

FIGURE III. THE DISTRIBUTION OF FLUX DENSITY IN DIFFERENT TEMPERATURE.

According to the result of fig.3, models of the demagnetized PM can be crated as fig.4. The material of irreversible demagnetization region is set to vacuum.

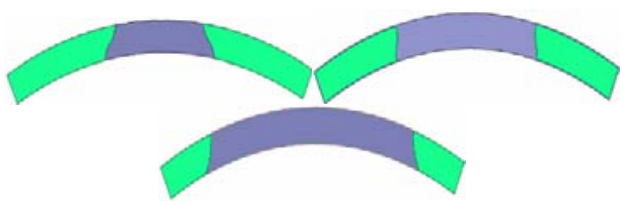
(a) $120^{\circ} \mathrm{C}$
(b) $140^{\circ} \mathrm{C}$
(c) $150^{\circ} \mathrm{C}$

FIGURE IV. MODEL OF THE DEMAGNETIZED PM.

\section{B. The Back EMF and Flux of Demagnetization}

Replace the PM with the fault model. Then, the back EMF and flux are calculated at the speed of 3200rpm and FFT analysis is adopted to analyze the harmonic wave, the results are shown in Table.2.

TABLE II. THE HARMONICS OF BACK EMF AND FLUX IN DIFFERENT STATE.

(a) The harmonics of phase back EMF (V)

\begin{tabular}{|c|c|c|c|c|}
\hline $\begin{array}{c}\text { Harmoni } \\
\text { c number }\end{array}$ & $\begin{array}{c}\text { Norma } \\
\text { I state }\end{array}$ & $\begin{array}{c}\mathbf{1 2 0}^{\circ} \mathbf{C} \\
\text { demagnetize } \\
\mathbf{d}\end{array}$ & $\begin{array}{c}\mathbf{1 4 0}^{\circ} \mathbf{C} \\
\text { demagnetize } \\
\mathbf{d}\end{array}$ & $\begin{array}{c}\mathbf{1 5 0}^{\circ} \mathbf{C} \\
\text { demagnetize } \\
\mathbf{d}\end{array}$ \\
\hline $\mathbf{1}$ & 105.53 & 60.08 & 42.65 & 18.44 \\
\hline $\mathbf{3}$ & 15.08 & 33.82 & 33.43 & 20.98 \\
\hline $\mathbf{5}$ & 0.34 & 0.58 & 0.98 & 1.2 \\
\hline $\mathbf{7}$ & 0.5 & 0.63 & 0.62 & 0.61 \\
\hline $\mathbf{9}$ & 0.22 & 2.84 & 3.09 & 2.03 \\
\hline $\mathbf{1 1}$ & 1.25 & 4.62 & 3.41 & 2.41 \\
\hline $\mathbf{1 3}$ & 0.28 & 1.18 & 0.62 & 0.54 \\
\hline $\mathbf{1 5}$ & 0.22 & 0.76 & 0.46 & 0.45 \\
\hline
\end{tabular}

(b) The harmonics of line back EMF (V)

\begin{tabular}{|c|c|c|c|c|}
\hline $\begin{array}{c}\text { Harmoni } \\
\mathbf{c} \\
\text { number }\end{array}$ & $\begin{array}{c}\text { Norma } \\
\text { l state }\end{array}$ & $\begin{array}{c}\mathbf{1 2 0}^{\circ} \mathbf{C} \\
\text { demagnetize } \\
\mathbf{d}\end{array}$ & $\begin{array}{c}\mathbf{1 4 0}^{\circ} \mathbf{C} \\
\text { demagnetize } \\
\mathbf{d}\end{array}$ & $\begin{array}{c}\mathbf{1 5 0}^{\circ} \mathbf{C} \\
\text { demagnetize } \\
\mathbf{d}\end{array}$ \\
\hline $\mathbf{1}$ & 183.29 & 104.09 & 73.61 & 31.79 \\
\hline $\mathbf{3}$ & 0.16 & 0.58 & 0.38 & 0.34 \\
\hline $\mathbf{5}$ & 0.15 & 1.45 & 1.66 & 3.99 \\
\hline $\mathbf{7}$ & 0.37 & 0.63 & 0.72 & 1.02 \\
\hline $\mathbf{9}$ & 0.03 & 0.5 & 0.38 & 0.29 \\
\hline $\mathbf{1 1}$ & 2.15 & 7.91 & 6.85 & 4.54 \\
\hline $\mathbf{1 3}$ & 0.48 & 2.13 & 1.02 & 0.89 \\
\hline $\mathbf{1 5}$ & 0.09 & 0.14 & 0.17 & 0.35 \\
\hline
\end{tabular}

(c) The harmonics of flux $\left(\times 10^{-3} \mathrm{~Wb}\right)$

\begin{tabular}{|c|c|c|c|c|}
\hline $\begin{array}{c}\text { Harmoni } \\
\text { C number }\end{array}$ & $\begin{array}{c}\text { Norma } \\
\text { I state }\end{array}$ & $\begin{array}{c}\mathbf{1 2 0}^{\circ} \mathbf{C} \\
\text { demagnetize } \\
\mathbf{d}\end{array}$ & $\begin{array}{c}\mathbf{1 4 0}^{\circ} \mathbf{C} \\
\text { demagnetize } \\
\mathbf{d}\end{array}$ & $\begin{array}{c}\mathbf{1 5 0}^{\circ} \mathbf{C} \\
\text { demagnetize } \\
\mathbf{d}\end{array}$ \\
\hline $\mathbf{1}$ & 104.9 & 59.7 & 42.4 & 18.2 \\
\hline $\mathbf{3}$ & 5.5 & 11.3 & 11.1 & 6.9 \\
\hline $\mathbf{5}$ & 0.1 & 0.3 & 0.4 & 0.5 \\
\hline $\mathbf{7}$ & 0.2 & 0.3 & 0.4 & 0.5 \\
\hline $\mathbf{9}$ & 0.2 & 0.5 & 0.4 & 0.3 \\
\hline $\mathbf{1 1}$ & 0.3 & 0.6 & 0.5 & 0.4 \\
\hline $\mathbf{1 3}$ & 0 & 0.4 & 0.2 & 0.1 \\
\hline $\mathbf{1 5}$ & 0.2 & 0.9 & 0.4 & 0.3 \\
\hline
\end{tabular}

As we can see in Table.2, for the demagnetized motor, except the amplitude of the fundamental wave, the amplitude of harmonic wave is higher than the motor at normal operation. Besides, it changes as the extent of demagnetization changes and the rules can be summarized as follow. Firstly, the phase EMF of the fifth harmonic increases as the extent of demagnetization increases. Secondly, the line EMF of the fifth, seventh and fifteenth harmonics increase when the 
demagnetization goes stronger. Thirdly, the fifth and seventh harmonics of the phase flux increase as the extent of demagnetization increases. Finally, the other harmonics decrease as the extent of demagnetization increases. With the rules all above, it can be concluded that the extent of demagnetization of PM can be obtained by analysis of the fifth and seventh harmonics.

\section{OPERATION BEHAVIORS OF DEMAGNETIZED PMSM}

When demagnetization fault happens, if operation continues, the system controller will try to make the motor back to the rated stated until the control current saturation. Therefore, the operation behavior will change and it may cause a secondary demagnetization. In order to analyze that, the demagnetized PMSM is operated as motor and generator and the operation behaviors are analyzed respectively.

\section{A. Operate as a Motor}

When working as a motor, the operation behavior in normal state and three demagnetization fault states are calculated at the output torque of $4 \mathrm{Nm}$. The results are shown in fig.5.

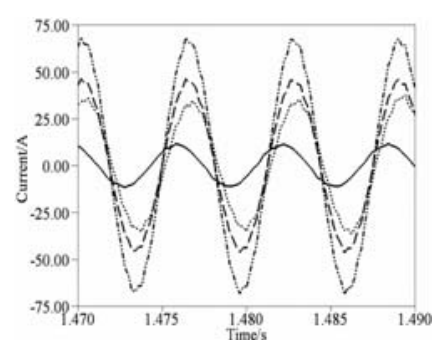

(a) Current

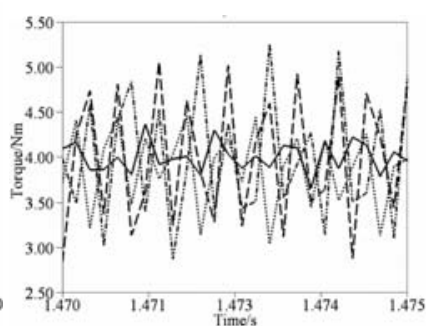

(b) Output torque
FIGURE V. THE WAVEFORMS OF CURRENT AND OUTPUT TORQUE WHEN OPERATE AS MOTOR.

From fig. 5 the fault current increases greatly as the extent of demagnetization increases and the fault current is 3.2 times, 4.6 times and 6 times as what is in normal state. Besides, the fluctuation of torque also increases greatly. The rate of fluctuation which is at 0.17 in normal state, increases to 0.49 , 0.55 and 0.6 respectively.

Because the current increases in demagnetized motor, the demagnetization region of PM may get larger. The flux density on PM in different state is shown in fig.6.

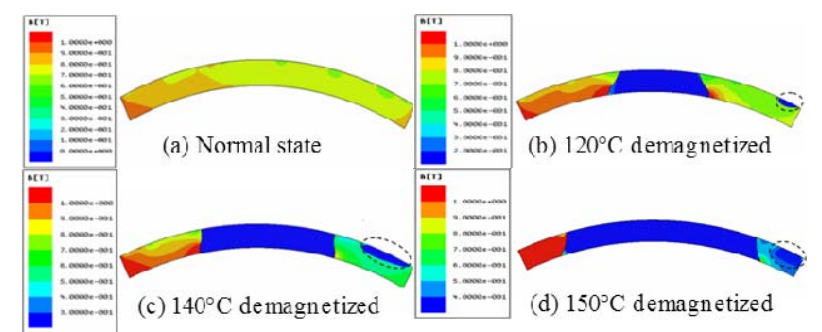

FIGURE VI. THE DISTRIBUTION OF FLUX DENSITY IN DIFFERENT STATE.

It can be seen in fig.6, the armature reaction leads a reduction of flux density in some part of the PM and some new irreversible demagnetization region appears. However, the flux density on other part of the PM increases.

\section{B. Operate as a Generator}

By the meaning of changing load resistance, the output power is adjusted to $1.4 \mathrm{~kW}$, when working as a generator. The results of current and electromagnetic torque are shown in fig.7.

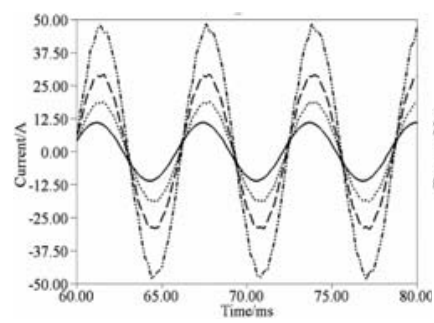

(a) Current

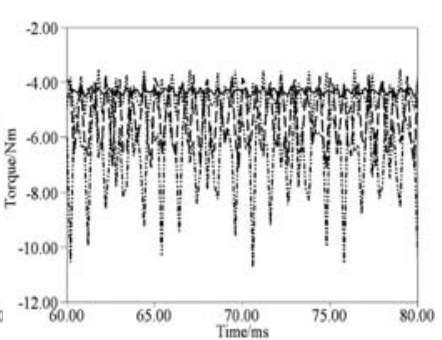

(b) Electromagnetic torque
FIGURE VII. THE WAVEFORMS OF CURRENT AND ELECTROMAGNETIC TORQUE WHEN OPERATE AS GENERATOR.

As it can be seen in fig.7, the current in winding increases to 1.7 times, 2.6 times and 4.3 times, in different temperature, as it in normal state. The electromagnetic torque increases to $4.6 \mathrm{Nm},-5.3 \mathrm{Nm}$ and $-6.6 \mathrm{Nm}$ respectively, while it is $-4.3 \mathrm{Nm}$ in normal state. Besides, the fluctuation increases as well in fault state. The flux density on the PM in different state is shown in fig.8.

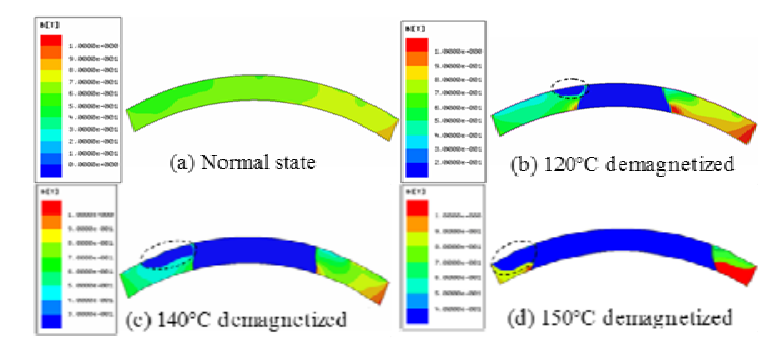

FIGURE VIII. THE DISTRIBUTION OF FLUX DENSITY IN DIFFERENT STATE.

From Fig.8 we can see that, some new irreversible demagnetization region appears, which is similar to when the PMSM operate as a motor, because of the stronger armature reaction. However the locations of these new demagnetization region are changed.

\section{SUMMARY}

The FEM is adopted to analyze the influence of threephase symmetrical short circuit on the demagnetization of PMSM. The result indicates that, for the three-phase symmetrical short circuit, the demagnetization caused by the transient current is worse than that caused by the steady current and the extent of demagnetization gets worse as the temperature increases. When demagnetization fault happens the back EMF and flux decreases greatly and the harmonics increase at the same time. This make it possible to realize the online monitoring of PMSM. If the motor operation continues, the demagnetization fault will increase the winding current, the fluctuation of torque, the temperature and vibration, besides it may cause a secondary demagnetization. The 
conclusions above lay a foundation for both further research on the demagnetization and the online monitoring of PMSM.

\section{ACKNOWLEDGEMENTS}

The work is financially supported by the project supported by the National Natural Science Foundation of China (Grant No.51477015).

\section{REFERENCE}

[1] W.H. Deng, S.Z. Ma. The superiority of the rare earth permanent magnet motor. Energy Conservation and Environmental Protection, 2002, (11):54.

[2] J.M. Huang, T.G. Jia. Status and development of the rare earth permanent magnet motor research. The Magazine on Equipment Machinery, 2010, (02):23-26.

[3] J. Tian, X.Q. Yang. A method of fault diagnosis of permanent magnet synchronous motor. Electric Machines \& Control Application. 2009,(8): 45-48.

[4] C. Ding. Research of about NdFeB permanent magnet electrical machines. China science and technology information, 2008, (22):143145.

[5] T. Hosoi, H. Watanabe, K. Shima, T. Fukami, R. Hanaoka, S. Takata. Demagnetization analysis of additional permanent magnets in salientpole synchronous machines under sudden short circuits. International Conference on Electrical Machines (ICEM), 2010: 1-6.

[6] W.X. Zhao, M. Cheng, W. Hua, Z.Z. Yang. Fault analysis and remedial strategy of doubly salient permanent magnet motors. Transactions of China Electrotechnical Society, 2009, (04):71 - 77

[7] D. Casadei, F. Filippetti, C. Rossi, A. Stefani. Magnets faults characterization for Permanent Magnet Synchronous Motors Diagnostics for Electric Machines. IEEE IS. on Power Electronics and Drives, 2009: $1-6$.

[8] K. C. Kim, S. B. Lim, D. H. Koo, J. Lee. The Shape Design of Permanent Magnet for Permanent Magnet Synchronous Motor Considering Partial Demagnetization. IEEE Trans on. Magn, 2002, 30(2): 622-624.

[9] K. Amir, F. Babak. A novel method for permanent magnet demagnetization fault detection and treatment in permanent magnet synchronous machine. IEEE Applied Power Electronics Conference and Exposition (APEC), 2010, (25): 2231-2237. 